\title{
Hospital costs of ischemic stroke and TIA in the Netherlands
}

Leander R. Buisman, MSc Siok Swan Tan, PhD

Paul J. Nederkoorn, MD, $\mathrm{PhD}$

Peter J. Koudstaal, MD, $\mathrm{PhD}$

William K. Redekop, $\mathrm{PhD}$

Correspondence to Dr. Buisman: buisman@bmg.eur.nl

\section{ABSTRACT}

Objectives: There have been no ischemic stroke costing studies since major improvements were implemented in stroke care. We therefore determined hospital resource use and costs of ischemic stroke and TIA in the Netherlands for 2012.

Methods: We conducted a retrospective cost analysis using individual patient data from a national diagnosis-related group registry. We analyzed 4 subgroups: inpatient ischemic stroke, inpatient TIA, outpatient ischemic stroke, and outpatient TIA. Costs of carotid endarterectomy and costs of an extra follow-up visit were also estimated. Unit costs were based on reference prices from the Dutch Healthcare Insurance Board and tariffs provided by the Dutch Healthcare Authority. Linear regression analysis was used to examine the association between hospital costs and various patient and hospital characteristics.

Results: A total of 35,903 ischemic stroke and 21,653 TIA patients were included. Inpatient costs were $€ 5,328(\$ 6,845)$ for ischemic stroke and $€ 2,470(\$ 3,173)$ for TIA. Outpatient costs were $€ 495$ (\$636) for ischemic stroke and $€ 587$ (\$754) for TIA. Costs of carotid endarterectomy were $€ 6,836(\$ 8,783)$. Costs of inpatient days were the largest contributor to hospital costs. Age, hospital type, and region were strongly associated with hospital costs.

Conclusions: Hospital costs are higher for inpatients and ischemic strokes compared with outpatients and TIAs, with length of stay (LOS) the most important contributor. LOS and hospital costs have substantially declined over the last 10 years, possibly due to improved hospital stroke care and efficient integrated stroke services. Neurology ${ }^{\circledR}$ 2015;84:2208-2215

\section{GLOSSARY}

CEA = carotid endarterectomy DBC $=$ Diagnose Behandeling Combinatie; LOS = length of stay; OECD = Organisation for Economic Co-operation and Development.

Ischemic stroke is the second most common cause of death and a major cause of disability, resulting in a large burden in current health care and societal costs. ${ }^{1}$ Advances in prevention and treatment of ischemic stroke and TIA during the past 2 decades have resulted in significant changes in medical practice, and therefore in improved clinical outcomes and potentially lower costs. ${ }^{1}$ A significant improvement was the organization of stroke care into integrated stroke services that reduced both mortality and disability. ${ }^{2}$ Furthermore, use of IV thrombolysis improved clinical outcome, ${ }^{3}$ and advances in secondary prevention, such as carotid endarterectomy (CEA), antiplatelet agents, blood pressure lowering, and cholesterol reduction, have proven to be effective. ${ }^{4-7}$

In the past, several studies have determined the costs of ischemic stroke in the Netherlands ${ }^{8-10}$ and other developed countries. ${ }^{11-14}$ However, these studies used resource use data from more than 10 years ago, before major improvements were implemented. At that time, treatment of stroke was far from optimal. On average, 10 of 28 inpatient days were explained by nonmedical reasons, most frequently waiting to be discharged to a nursing home. ${ }^{15}$ One would expect that the improvements in patient management reduced the length of stay (LOS) and therefore 
hospital costs of ischemic stroke. Therefore, the aim of this study was to determine hospital resource use and costs of ischemic stroke and TIA in the Netherlands for 2012. The secondary aim was to examine the association between hospital costs of ischemic stroke and TIA and various patient and hospital characteristics.

METHODS Patient population. The patient population included patients with a recent ischemic stroke or TIA. Ischemic stroke was defined as a focal neurologic deficit of sudden onset of presumed vascular origin, lasting at least 24 hours, with brain imaging showing typical signs of brain infarction or no abnormalities. The diagnosis of TIA was defined as a focal neurologic deficit of sudden onset lasting less than 24 hours and with no signs of recent infarction on CT scan.

Four subgroups were analyzed: inpatient ischemic stroke, inpatient TIA, outpatient ischemic stroke, and outpatient TIA. Additionally, we estimated the costs of CEA, and costs of an extra follow-up visit necessary because of (1) direct consequences of the ischemic event, such as cognitive dysfunction, inability to return to work, anxiety, headache, or epilepsy, or (2) management of vascular risk factors, such as uncontrolled hypertension, hypercholesterolemia, or obesity. The costs of CEA and the costs of an extra follow-up visit are costs in addition to those of 1 of the 4 subgroups when a patient underwent CEA or had an extra follow-up visit, respectively.

Data. We performed a retrospective cost analysis using patient and resource use data from 2010 from the Diagnose Behandeling Combinatie (DBC) (diagnosis treatment combination) case mix system, a diagnosis-related group-like system that contains resource use data of all hospitalizations in the Netherlands. The length of follow-up is patient-specific for both inpatients and outpatients. It starts on the day of first hospital admission after a recent ischemic stroke or TIA to a maximum of 42 days for inpatients and 90 days for outpatients following the starting date. The length of follow-up included acute hospitalization, readmission for the same ischemic event, hospital allied health services, and hospital outpatient visits in the same hospital. A new follow-up was started and a new DBC was opened if a patient was seen after the maximum length of follow-up, at another hospital, or for a new ischemic event.

Hospital costs were determined by multiplying the resource use by the corresponding unit costs for 2012. Resource use focused on the hospital only and included inpatient days, intensive care days, outpatient and emergency room visits, ambulatory treatment, diagnostic and imaging tests, allied health services, and laboratory investigations (i.e., laboratory, microbiology, pathology, and blood products). The unit costs of inpatient days, intensive care days, outpatient visits, emergency room visits, ambulatory treatment, and allied health services were based on reference prices of the Dutch Manual of Costing. ${ }^{16}$ The Dutch

Table 1 Patient and hospital characteristics of 4 patient subgroups

\begin{tabular}{|c|c|c|c|c|}
\hline & $\begin{array}{l}\text { Inpatient ischemic } \\
\text { stroke }\end{array}$ & Inpatient TIA & $\begin{array}{l}\text { Outpatient ischemic } \\
\text { stroke }\end{array}$ & Outpatient TIA \\
\hline No. of patients & 24,671 & 4,596 & 11,232 & 17,057 \\
\hline Age, $y$, mean $\pm S D$ & $71 \pm 14$ & $69 \pm 13$ & $69 \pm 13$ & $68 \pm 13$ \\
\hline Men, \% & 50 & 53 & 53 & 50 \\
\hline \multicolumn{5}{|l|}{ Hospital type, \% } \\
\hline Academic & 9 & 7 & 9 & 8 \\
\hline Nonacademic (teaching) & 28 & 26 & 25 & 26 \\
\hline Nonacademic (large) & 20 & 25 & 20 & 21 \\
\hline Nonacademic (midsized) & 14 & 11 & 12 & 11 \\
\hline Nonacademic (small) & 25 & 28 & 29 & 28 \\
\hline Nonacademic (type unknown) & 4 & 3 & 5 & 6 \\
\hline \multicolumn{5}{|l|}{ Region, \% } \\
\hline Drenthe & 3 & 3 & 4 & 4 \\
\hline Flevoland & 2 & 2 & 2 & 2 \\
\hline Friesland & 3 & 4 & 4 & 3 \\
\hline Gelderland & 13 & 12 & 11 & 13 \\
\hline Groningen & 4 & 3 & 4 & 3 \\
\hline Limburg & 8 & 7 & 10 & 10 \\
\hline North Brabant & 15 & 14 & 19 & 19 \\
\hline North Holland & 15 & 15 & 16 & 13 \\
\hline Overijssel & 6 & 5 & 4 & 6 \\
\hline South Holland & 22 & 21 & 18 & 21 \\
\hline Utrecht & 6 & 12 & 6 & 6 \\
\hline Zeeland & 3 & 4 & 2 & 2 \\
\hline
\end{tabular}


Manual of Costing provides a list of reference prices for different types of care to facilitate the standardization and comparability of economic evaluations. A reference price is an average unit cost estimated on the basis of large, diverse populations that can be directly used to value resource quantities. The unit costs of diagnostic and imaging tests and laboratory investigations were based on tariffs provided by the Dutch Healthcare Authority. ${ }^{17}$ The unit costs of surgery were estimated based on internal cost prices from a Dutch academic hospital. All unit costs reflected full hospital costs, including material, labor, drug, overhead, and capital costs. Where necessary, unit costs were adjusted to 2012 Euros using the general price index from the Dutch Central Bureau of Statistics. ${ }^{18}$ We have converted Euros to US dollars and added that information parenthetically. A mean exchange rate of $€ 1=\$ 1.2848$ was used for 2012 , because the daily exchange rates ranged from $€ 1=\$ 1.2089$ to $€ 1=$ $\$ 1.3454$ in $2012 .{ }^{19}$

Regression analysis. Three ordinary least squares regression analyses were performed for 3 patient groups to examine the association between hospital costs and various patient and hospital characteristics: inpatient ischemic stroke and TIA (analysis 1), outpatient ischemic stroke and TIA (analysis 2), and patients who underwent CEA (analysis 3). In each analysis, hospital costs were the dependent variable. The independent variables were various patient and hospital characteristics. The patient variables were age, sex, and the interaction between age and sex. Age was estimated using the midpoint of each 5-year category (i.e., 63 years was used if the 5-year category was 61-65 years). The hospital characteristics included hospital type (academic and different type of nonacademic hospitals) and region in the Netherlands. The geographical regions used were the 12 Dutch provinces. In demographic and economic terms, these provinces can be classified into 2 areas: a metropolitan area including the 4 largest Dutch cities (in the provinces North Holland, South Holland, Utrecht, and Flevoland) and the rest of the Netherlands. The metropolitan area has developed in an advanced economy in many leading sectors, has the lowest unemployment rates in the Organisation for Economic
Co-operation and Development (OECD), and is one of the most densely populated areas in the OECD. ${ }^{20}$ Statistical inference of associations was calculated using the 2-tailed $t$ test.

RESULTS Descriptive statistics. Table 1 shows the patient and hospital characteristics of the 4 patient subgroups: inpatient ischemic stroke, inpatient TIA, outpatient ischemic stroke, and outpatient TIA. A total of 24,671 inpatient ischemic stroke patients and 4,596 inpatient TIA patients were admitted to any Dutch hospital in 2010 (table 1). In the outpatient setting, 11,232 ischemic stroke patients and 17,057 TIA patients were admitted to any Dutch hospital in 2010.

Moreover, table 1 shows that ischemic stroke patients are on average older than TIA patients (inpatient: $71 \pm 14[$ mean \pm SD] vs $69 \pm 13, p<$ 0.0001; outpatient: $69 \pm 13$ vs $68 \pm 13, p<$ 0.0001 ) and that inpatient TIA and outpatient ischemic stroke had a slightly higher proportion of men. We observed no large differences among the 4 patient subgroups in the proportion of patients admitted per hospital type and region. Table 1 shows that most patients were admitted to small nonacademic hospitals, followed by teaching and large nonacademic hospitals. Most patients were admitted in the most densely populated provinces (South Holland, North Holland, and North Brabant).

In addition, 3.3\% $(1,891 / 57,556)$ of the ischemic stroke patients and TIA patients admitted to a hospital in 2010 underwent CEA. Of the inpatients alone, $6.5 \%(1,891 / 29,267)$ underwent CEA, the mean age was $70 \pm 10$ years, and about two-thirds were men. Furthermore, $65 \%(1,231 / 1,891)$ of CEAs were

Figure Distribution of length of stay

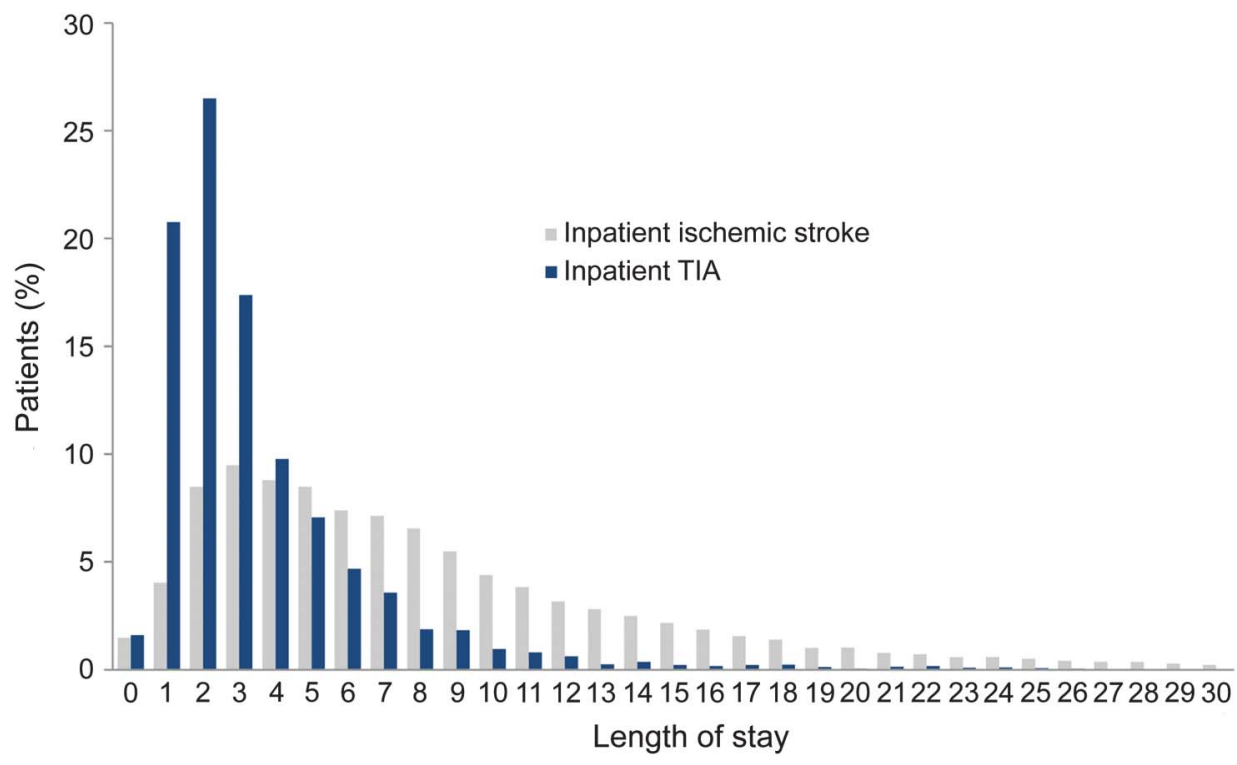

Inpatient ischemic stroke $\mathrm{n}=24,671$; inpatient TIA $\mathrm{n}=4,596$. 
performed in academic, teaching nonacademic, or large nonacademic hospitals.

In total, $12 \%(6,868 / 57,556)$ of the patients who visited the hospital in 2010 (either inpatient or outpatient) had an extra follow-up visit. Of these patients, $92 \%(6,303 / 6,828)$ visited the outpatient clinic. The mean age of outpatients with an extra follow-up visit was $64 \pm 14$ vs $67 \pm 14$ years for inpatients $(p<$ 0.0001 ) and in both settings $54 \%$ were men.

Length of stay. The figure shows the distribution of LOS for inpatient ischemic stroke and inpatient TIA patients up to 30 days; $2.1 \%$ of inpatient ischemic strokes and $0.2 \%$ of inpatient TIAs have more than 30 inpatient days. The average LOS of inpatient TIA patients was shorter than that of inpatient ischemic stroke patients ( 3.6 vs 8.8 days, $p<0.0001$ ), which is mainly caused by the higher proportion of TIA patients with 1-4 inpatient days and lower proportion of longer stays than ischemic stroke patients. About $1.5 \%$ of inpatient ischemic stroke and inpatient TIA patients had zero inpatient days, probably because they died within 24 hours after hospital admission.

Costs of ischemic stroke and TIA. Table 2 presents the unit costs of the different cost items, breakdown of average resource use, and average hospital costs per subgroup. Average hospital costs were $€ 5,328 \pm$ $€ 4,346(\$ 6,845 \pm \$ 5,584)$ for inpatient ischemic stroke, $€ 2,470 \pm € 1,939(\$ 3,173 \pm \$ 2,491)$ for inpatient TIA, $€ 495 \pm € 333(\$ 636 \pm \$ 428)$ for

Table 2 Unit costs, average resource use, and average costs of inpatient and outpatient ischemic stroke and TIA

\begin{tabular}{|c|c|c|c|c|c|c|c|c|c|}
\hline Cost item & Unit costs & \multicolumn{4}{|c|}{ Average resource use per patient } & \multicolumn{4}{|c|}{ Average costs per patient } \\
\hline \multicolumn{10}{|l|}{ LOS } \\
\hline Inpatient days & $€ 485$ & 8.794 & 3.602 & 0.006 & 0.002 & $€ 4,269$ & $€ 1,748$ & $€ 3$ & $€ 1$ \\
\hline Outpatient visits & $€ 76$ & 0.799 & 0.810 & 0.890 & 0.843 & $€ 61$ & $€ 62$ & $€ 68$ & $€ 64$ \\
\hline Emergency room visits & $€ 160$ & 0.889 & 0.868 & 0.256 & 0.242 & $€ 143$ & $€ 139$ & $€ 41$ & $€ 39$ \\
\hline Ambulatory treatment & $€ 267$ & 0.013 & 0.035 & 0.236 & 0.514 & $€ 3$ & $€ 9$ & $€ 63$ & $€ 137$ \\
\hline \multicolumn{10}{|l|}{ Diagnostic and imaging tests } \\
\hline ECG & $€ 20$ & 0.775 & 0.701 & 0.383 & 0.581 & $€ 15$ & $€ 14$ & $€ 8$ & $€ 12$ \\
\hline X-ray (thorax) & $€ 51$ & 0.429 & 0.243 & 0.099 & 0.129 & $€ 22$ & $€ 12$ & $€ 5$ & $€ 7$ \\
\hline MRI (brain) & $€ 253$ & 0.249 & 0.178 & 0.281 & 0.162 & $€ 63$ & $€ 45$ & $€ 71$ & $€ 41$ \\
\hline EEG & $€ 73$ & 0.120 & 0.194 & 0.079 & 0.093 & $€ 9$ & $€ 14$ & $€ 6$ & $€ 7$ \\
\hline Diagnostic services (other) & $€ 129$ & 0.604 & 0.451 & 0.315 & 0.322 & $€ 78$ & $€ 58$ & $€ 41$ & $€ 41$ \\
\hline \multicolumn{10}{|l|}{ Allied health services } \\
\hline Physical therapy & $€ 38$ & 2.975 & 0.532 & 0.010 & 0.002 & $€ 114$ & $€ 20$ & $€ 0$ & $€ 0$ \\
\hline Occupational therapy & $€ 24$ & 1.775 & 0.271 & 0.015 & 0.000 & $€ 42$ & $€ 6$ & $€ 0$ & $€ 0$ \\
\hline Speech therapy & $€ 35$ & 1.505 & 0.239 & 0.020 & 0.007 & $€ 53$ & $€ 8$ & $€ 1$ & $€ 0$ \\
\hline Blood (derived) products & $€ 219$ & 0.014 & 0.005 & 0.003 & 0.001 & $€ 3$ & $€ 1$ & $€ 1$ & $€ 0$ \\
\hline Total & & & & & & $€ 5,328$ & $€ 2,470$ & $€ 495$ & $€ 587$ \\
\hline
\end{tabular}

Abbreviations: IS = ischemic stroke; LOS = length of stay.

Inpatient ischemic stroke $n=24,671$; outpatient ischemic stroke $n=11,232$; inpatient TIA $n=4,596$; outpatient TIA $n=17,057$. 
outpatient ischemic stroke, and $€ 587 \pm € 303$ (\$754 \pm \$389) for outpatient TIA.

Costs of inpatient days were the largest contributor to costs of both inpatient ischemic stroke $(80 \%)$ and inpatient TIA (71\%). Diagnostic and imaging tests were the second largest contributor to costs of both inpatient groups. However, the contribution was substantially larger for TIA (17\%) than for ischemic stroke (9\%). The share of visits (i.e., outpatient, emergency room, and ambulatory treatment) was the third largest contributor for both inpatient groups.

A different pattern was observed in the contribution of outpatient costs. Costs of diagnostic and imaging tests were the largest contributor for both

\begin{tabular}{|c|c|c|c|}
\hline \multicolumn{4}{|c|}{$\begin{array}{l}\text { Unit costs, average resource use, and average costs of carotid } \\
\text { endarterectomy }\end{array}$} \\
\hline Cost item & Unit costs & $\begin{array}{l}\text { Average resource } \\
\text { use per patient }\end{array}$ & $\begin{array}{l}\text { Average costs } \\
\text { per patient }\end{array}$ \\
\hline \multicolumn{4}{|l|}{ LOS } \\
\hline Inpatient days & $€ 485$ & 4.828 & $€ 2,343$ \\
\hline Intensive care days & $€ 2,319$ & 0.052 & $€ 120$ \\
\hline \multicolumn{4}{|l|}{ Visits } \\
\hline Outpatient visits & $€ 76$ & 0.750 & $€ 57$ \\
\hline Emergency room visits & $€ 160$ & 0.077 & $€ 12$ \\
\hline Ambulatory treatment & $€ 267$ & 0.008 & $€ 2$ \\
\hline \multicolumn{4}{|l|}{ Diagnostic and imaging tests } \\
\hline СТ (brain) & $€ 197$ & 0.055 & $€ 11$ \\
\hline Duplex (carotid) & $€ 85$ & 1.161 & $€ 99$ \\
\hline ECG & $€ 20$ & 0.265 & $€ 5$ \\
\hline X-ray (thorax) & $€ 51$ & 0.166 & $€ 8$ \\
\hline MRI (brain) & $€ 253$ & 0.007 & $€ 2$ \\
\hline EEG & $€ 73$ & 0.457 & $€ 33$ \\
\hline Diagnostic services (other) & $€ 129$ & 0.951 & $€ 122$ \\
\hline \multicolumn{4}{|l|}{ Surgery } \\
\hline Carotid endarterectomy & $€ 3,486$ & 1.000 & $€ 3,486$ \\
\hline Surgery (other) & $€ 3,486$ & 0.129 & $€ 450$ \\
\hline \multicolumn{4}{|l|}{ Allied health services } \\
\hline Physical therapy & $€ 38$ & 0.292 & $€ 11$ \\
\hline Occupational therapy & $€ 24$ & 0.035 & $€ 1$ \\
\hline Speech therapy & $€ 35$ & 0.053 & $€ 2$ \\
\hline Psycho therapy & $€ 82$ & 0.000 & $€ 0$ \\
\hline \multicolumn{4}{|l|}{ Laboratory investigations } \\
\hline Laboratory services & $€ 13$ & 3.369 & $€ 45$ \\
\hline Microbiological services & $€ 15$ & 0.542 & $€ 8$ \\
\hline Pathologic services & $€ 91$ & 0.118 & $€ 11$ \\
\hline Blood (derived) products & $€ 219$ & 0.031 & $€ 7$ \\
\hline Total & & & $€ 6,836$ \\
\hline
\end{tabular}

LOS = length of stay.

Carotid endarterectomy $n=1,891$. ischemic stroke (61\%) and TIA (57\%). Visits were the second largest contributor to outpatient costs (ischemic stroke 35\%, TIA 41\%).

Differences in costs between inpatients and outpatients were mainly caused by this difference in LOS. In addition to costs related to LOS, other contributors to higher costs for inpatients included more frequent use of laboratory and allied health services.

Costs of CEA. Table 3 shows the unit costs of the different cost items, breakdown of average resource use, and average hospital costs of patients who underwent CEA. Average costs of these patients were $€ 6,836 \pm € 2,862(\$ 8,783 \pm \$ 3,677)$, with surgery $(51 \%)$ and inpatient days (34\%) as main components.

Costs of an extra follow-up visit. Substantial differences were observed in average hospital costs per patient between inpatients and outpatients, which were mainly caused by the average LOS of inpatient ischemic stroke (7.6 days) and inpatient TIA (4.8 days) $(p<0.01)$. Average costs of inpatients who had an extra follow-up visit after ischemic stroke were $€ 4,567 \pm € 5,817(\$ 5,868 \pm \$ 7,474)$ and after TIA $€ 2,983 \pm € 3,368(\$ 3,833 \pm \$ 4,327)$. The average costs of outpatients with an extra follow-up visit were $€ 223 \pm € 282$ (\$287 \pm \$362) for ischemic stroke and $€ 229 \pm € 316(\$ 294 \pm \$ 406)$ for TIA. The largest component of outpatient costs was outpatient visits.

Regression analysis. The regression analyses indicate that the overall regression models are statistically significant. However, the explained variance is low $(2.1 \%-5.6 \%)$. Table 4 shows the associations between hospital costs and the various patient and hospital characteristics of inpatient care for ischemic stroke and TIA (analysis 1), outpatient care for ischemic stroke and TIA (analysis 2), and CEA (analysis 3). Inpatient costs were significantly related to age (i.e., one additional year of age was associated with a cost increase of $€ 25$ [\$32]). The impact of age on inpatient costs was high (e.g., a 20-year age difference results in additional costs of $€ 500$ [\$640]). Moreover, analysis 1 shows that costs at teaching, small, and unknown type of nonacademic hospitals were significantly higher than at academic hospitals, and that inpatient costs at hospitals located in Drenthe, Flevoland, Groningen, Limburg, North Brabant, and Overijssel were significantly higher than in South Holland.

Outpatient costs of ischemic stroke and TIA were significantly associated with age. Outpatient costs decrease by $€ 2$ (\$3) for each additional year of age and no difference was observed between sexes. Significant differences in outpatient costs were found 


\begin{tabular}{|c|c|c|c|}
\hline \multirow[t]{2}{*}{ Table 4} & \multicolumn{3}{|c|}{$\begin{array}{l}\text { Association between hospital costs and patient and hospital } \\
\text { characteristics }\end{array}$} \\
\hline & $\begin{array}{l}\text { Analysis 1: } \\
\text { Inpatient care, } \\
\text { coefficient (SE) }\end{array}$ & $\begin{array}{l}\text { Analysis 2: } \\
\text { Outpatient care, } \\
\text { coefficient (SE) }\end{array}$ & $\begin{array}{l}\text { Analysis 3: Carotid } \\
\text { endarterectomy, } \\
\text { coefficient (SE) }\end{array}$ \\
\hline \multicolumn{4}{|l|}{$\begin{array}{l}\text { Patient } \\
\text { characteristics }\end{array}$} \\
\hline Age & $25(3)^{a}$ & $-2(0)^{a}$ & $31(11)^{a}$ \\
\hline Male & $-417(265)$ & $30(20)$ & 457 (961) \\
\hline Age $\times$ male & $5(4)$ & $0(0)$ & $-13(14)$ \\
\hline \multicolumn{4}{|l|}{$\begin{array}{l}\text { Hospital } \\
\text { characteristics }\end{array}$} \\
\hline \multicolumn{4}{|l|}{ Hospital type } \\
\hline Academic & ref. & ref. & ref. \\
\hline $\begin{array}{l}\text { Nonacademic } \\
\text { (teaching) }\end{array}$ & $613(102)^{a}$ & $71(8)^{a}$ & 272 (200) \\
\hline $\begin{array}{l}\text { Nonacademic } \\
\text { (large) }\end{array}$ & $-114(113)$ & $34(9)^{a}$ & -21 (235) \\
\hline $\begin{array}{l}\text { Nonacademic } \\
\text { (midsized) }\end{array}$ & 73 (102) & $-3(8)$ & $-852(206)^{a}$ \\
\hline $\begin{array}{l}\text { Nonacademic } \\
\text { (small) }\end{array}$ & $362(108)^{a}$ & $55(8)^{a}$ & $665(323)^{b}$ \\
\hline $\begin{array}{l}\text { Nonacademic } \\
\text { (unknown) }\end{array}$ & $855(155)^{a}$ & $22(11)^{\mathrm{b}}$ & 106 (332) \\
\hline \multicolumn{4}{|l|}{ Region } \\
\hline Drenthe & $958(150)^{a}$ & $14(11)$ & $-1,119(397)^{a}$ \\
\hline Flevoland & $482(205)^{b}$ & $-70(15)^{\mathrm{a}}$ & $-950(562)^{c}$ \\
\hline Friesland & $179(143)$ & $-143(12)^{a}$ & $-1,450(394)^{a}$ \\
\hline Gelderland & $-21(86)$ & $-16(7)^{b}$ & $-872(245)^{\mathrm{a}}$ \\
\hline Groningen & $245(146)^{c}$ & $-77(12)^{a}$ & $-183(413)$ \\
\hline Limburg & $645(103)^{a}$ & $-28(8)^{a}$ & $-980(264)^{a}$ \\
\hline North Brabant & $492(83)^{a}$ & $-41(6)^{a}$ & $-570(225)^{b}$ \\
\hline North Holland & 99 (83) & $-20(7)^{a}$ & $-739(240)^{\mathrm{a}}$ \\
\hline Overijssel & $1,320(118)^{a}$ & 7 (9) & $-1,116(327)^{a}$ \\
\hline South Holland & ref. & ref. & ref. \\
\hline Utrecht & $50(111)$ & $19(10)^{c}$ & $-1,307(303)^{a}$ \\
\hline Zeeland & 209 (164) & $-118(15)^{a}$ & $-1,513(696)^{b}$ \\
\hline $\begin{array}{l}\text { No. of } \\
\text { observations }\end{array}$ & 28,655 & 27,740 & 1,861 \\
\hline$R^{2}, \%$ & 2.1 & 2.6 & 5.6 \\
\hline $\begin{array}{l}\text { obreviation: ref. }= \\
<0.01 \\
<0.05 \\
<0.1\end{array}$ & rence category. & & \\
\hline
\end{tabular}

between academic and all types of nonacademic hospitals, except midsized nonacademic hospitals. Moreover, outpatient costs at hospitals located in most provinces were significantly lower than in South Holland.

Hospital costs of patients who underwent CEA were significantly related to age and region. Costs of CEA were significantly lower in all provinces compared to South Holland (except for Groningen), ranging from $€ 570$ to $€ 1,513$ (\$732 to $\$ 1,944)$ lower costs. In addition, significant differences were found between academic and midsized and small nonacademic hospitals.

Subsequent analysis. We performed a subsequent analysis to examine whether hospital costs and LOS were associated with admission day of the week. We found that both LOS and costs were significantly lower on Mondays, Tuesdays, Wednesdays, and Thursdays compared to the other days of the week $(p<0.1)$.

DISCUSSION This study is the first and most extensive cost analysis of inpatient and outpatient hospital costs of ischemic stroke and TIA in the last 10 years. Costs between inpatient and outpatient care for ischemic stroke and TIA differed extensively and were largely attributable to inpatient hospital stay. The cost difference between inpatient ischemic stroke $(€ 5,328 / \$ 6,845)$ and inpatient TIA (€2,470/ $\$ 3,173$ ) was caused by a shorter LOS for TIA patients (3.6 days vs 8.8 for ischemic stroke), which could have been expected given the lower severity and shorter symptom duration of TIA. ${ }^{21}$ Costs of outpatient care were higher for TIA than for ischemic stroke due to more frequent use of ambulatory treatment and diagnostic and imaging tests.

During the last 2 decades, LOS and costs of ischemic stroke have been substantially reduced, possibly due to major improvements in patient management (e.g., the organization of stroke care into integrated stroke services and the use of IV thrombolysis). Two studies from the early 1990 s estimated an average LOS of 27 days $^{8}$ and 28 days. ${ }^{15}$ A study performed in the late 1990s examined the ability of 3 experimental stroke services to reduce LOS. Only one hospital succeeded (13 days vs 32 and 33 in the 2 other hospitals). ${ }^{10} \mathrm{We}$ found that the average LOS for ischemic stroke had been considerably reduced to 8.8 days in 2010. In terms of hospital costs per patient, the difference of about 20 inpatient days alone has resulted in a cost reduction of $€ 9,700(\$ 12,460)$ in 2012, with a unit cost of $€ 485$ (\$623) per inpatient day. On the other hand, IV thrombolysis and other novel therapeutic options have increased the unit costs of an inpatient day.

Our finding that age, hospital type, and region were associated with hospital costs partially correspond with the results of an earlier study that found hospital costs to be dependent on region as well as stroke severity at discharge, waiting lists for nursing home care, and death from stroke in the acute phase. However, in that study, age was not found to be associated with hospital costs and hospital type was not considered. ${ }^{10}$ Our regression analyses show significant associations between hospital costs and both hospital type and region. Both inpatient and outpatient costs were significantly higher at teaching, small, and 
unknown type of nonacademic hospitals compared to academic hospitals. The analyses also show that inpatient costs are significantly higher and outpatient costs significantly lower in most of the provinces outside the Dutch metropolitan area. A possible explanation is that the patient case mix differs between hospital types and regions. Moreover, we found that LOS was associated with admission day of the week. A possible explanation is that LOS is shorter when patients are admitted during weekdays due to the availability of medical personnel. This finding and the determinants of hospital costs, such as hospital type and region, merit further research.

In addition, we found that more than $90 \%$ of patients with an extra follow-up visit were outpatients. We assume that inpatients were discharged to longterm care facilities where they received the necessary follow-up care. In contrast, the patients who were originally seen at the hospital's outpatient clinic were discharged directly home and therefore sometimes needed an extra follow-up visit.

The strength of our study is that we examined the hospital costs and LOS using data from all patients in the Netherlands who were seen at any hospital for an ischemic stroke or TIA in 2010. Our findings are highly relevant for neurologists since they reflect the costs of current patient care. The methods we used in our study can also be used by clinicians as an example to perform similar analyses for other diseases. In addition, our results may be used as input for economic evaluations to support decision-making about reimbursement, investment, and pricing of health care interventions.

Our study also has some limitations. The DBC database does not contain information on stroke severity, such as the NIH Stroke Scale or the modified Rankin Scale, and the most probable cause, such as the Trial of ORG 10172 in Acute Stroke Treatment classification. Potential proxy measures of stroke severity, such as clinical parameters and discharge location, were also not included in the DBC database. We were therefore unable to estimate the costs and LOS for different types of ischemic events. Furthermore, we were unable to assess potential risk factors and comorbidity that determine hospital costs, such as diabetes mellitus, hypertension, and hyperlipidemia. ${ }^{22}$ Moreover, the database includes only hospital care. The costs of stroke care outside hospitals (e.g., general practitioners, rehabilitation centers, longterm care facilities, and nursing home care) could not be estimated with the database. Further research should estimate these costs to obtain a total estimate of costs of ischemic stroke and TIA.

Some of our results are not necessarily generalizable to different health care systems. For example, the absolute costs seen in our study do not necessarily reflect the costs expected elsewhere because, for example, the unit costs of particular components of stroke care (cost per inpatient day) differ between countries and health care systems. However, we expect that the trends and patterns in stroke care found in our study (e.g., reduction in length of stay and differences between hospital types and regions) are likely to be generalizable.

We have shown that hospital costs are higher for inpatients and ischemic strokes compared with outpatients and TIAs, with LOS as the most important contributor. LOS and hospital costs have been substantially reduced over the past 10 years, possibly due to improved hospital stroke care and efficient integrated stroke services.

\section{AUTHOR CONTRIBUTIONS}

Leander R. Buisman drafted and revised the manuscript for content, including medical writing for content, contributed to the design of the study, analyzed and interpreted the data, acquired the data, performed the statistical analysis, and handled the study coordination. Siok Swan Tan revised the manuscript for content, including medical writing for content, contributed to the design of the study, interpreted the data, handled the study supervision, and obtained study funding. Paul J. Nederkoorn revised the manuscript for content, including medical writing for content. Peter J. Koudstaal revised the manuscript for content, including medical writing for content, contributed to the design of the study, and interpreted the data. William K. Redekop revised the manuscript for content, including medical writing for content, contributed to the design of the study, interpreted the data, handled the study supervision, and obtained study funding. All authors gave final approval for publication of this manuscript.

\section{ACKNOWLEDGMENT}

The authors thank Joke Hendriks, Frank van den Boogert, and Tamara van Kleef for their assistance in estimating specific unit costs.

\section{STUDY FUNDING}

This research was performed within the framework of CTMM, the Center for Translational Molecular Medicine (www.ctmm.nl), project PARISk (grant 01C-202), and supported by the Dutch Heart Foundation and Dutch Organisation for Health Research and Healthcare Innovation (ZON-MW, grant no. 152002043).

\section{DISCLOSURE}

The authors report no disclosures relevant to the manuscript. Go to Neurology.org for full disclosures.

Received August 15, 2014. Accepted in final form December 18, 2014.

\section{REFERENCES}

1. Donnan GA, Fisher M, Macleod M, Davis SM. Stroke. Lancet 2008;371:1612-1623.

2. Minkman MM, Schouten LM, Huijsman R, van Splunteren PT. Integrated care for patients with a stroke in the Netherlands: results and experiences from a national Breakthrough Collaborative Improvement project. Int J Integr Care 2005;5:e14.

3. Saver JL, Fonarow GC, Smith EE, et al. Time to treatment with intravenous tissue plasminogen activator and outcome from acute ischemic stroke. JAMA 2013;309: 2480-2488.

4. North American Symptomatic Carotid Endarterectomy Trial Collaborators. Beneficial effect of carotid endarterectomy in 
symptomatic patients with high-grade carotid stenosis. N Engl J Med 1991;325:445-453.

5. European Carotid Surgery Trialists' Collaborative Group. MRC European Carotid Surgery Trial: interim results for symptomatic patients with severe (70-99\%) or with mild (0-29\%) carotid stenosis. Lancet 1991;337:1235-1243.

6. PROGRESS Collaborative Group. Randomised trial of a perindopril-based blood pressure lowering regimen among 6,105 patients with prior stroke or transient ischaemic attack. Lancet 2001;358:1033-1041.

7. Amarenco P, Bogousslavsky J, Callahan A, et al. High-dose atorvastatin after stroke or transient ischemic attack. N Engl J Med 2006;355:549-559.

8. Bergman L, van der Meulen J, Limburg M, Habbema DF. Cost of medical care after first-ever stroke in the Netherlands. Stroke 1995;26:1830-1836.

9. Evers SM, Engel GL, Ament AJ. Cost of stroke in the Netherlands from a societal perspective. Stroke 1997;28: 1375-1381.

10. Van Exel J, Koopmanschap MA, Van Wijngaarden JD, Scholte Op Reimer WJ. Costs of stroke and stroke services: determinants of patient costs and a comparison of costs of regular care and care organised in stroke services. Cost Eff Resour Alloc 2003;1:2.

11. Kolominsky-Rabas PL, Heuschmann PU, Marschall D, et al. Lifetime cost of ischemic stroke in Germany: results and national projections from a population-based stroke registry: the Erlangen Stroke Project. Stroke 2006;37:1179-1183.

12. Gioldasis G, Talelli P, Chroni E, Daouli J, Papapetropoulos T, Ellul J. In-hospital direct cost of acute ischemic and hemorrhagic stroke in Greece. Acta Neurol Scand 2008;118:268-274.

13. Cadilhac DA, Carter R, Thrift AG, Dewey HM. Estimating the long-term costs of ischemic and hemorrhagic stroke for Australia: new evidence derived from the North
East Melbourne Stroke Incidence Study (NEMESIS). Stroke 2009;40:915-921.

14. Yoneda Y, Okuda S, Hamada R, et al. Hospital cost of ischemic stroke and intracerebral hemorrhage in Japanese stroke centers. Health Policy 2005;73:202-211.

15. Van Straten A, Van der Meulen JH, Van den Bos GA, Limburg M. Length of hospital stay and discharge delays in stroke patients. Stroke 1997;28:137-140.

16. Tan SS, Bouwmans CA, Rutten FF, Hakkaart-van Roijen L. Update of the Dutch manual for costing in economic evaluations. Int $\mathrm{J}$ Technol Assess Health Care 2012;28:152-158.

17. Dutch Healthcare Authority (in Dutch: Nederlandse Zorgauthoriteit, NZa). NZa Zorgproducten Tariefapplicatie. Available at: http://dbc-zorgproducten-tarieven. nza.nl/nzaZpTarief/ZoekfunctieDbc.aspx. Accessed May $1,2013$.

18. Statistics Netherlands (in Dutch: Central Bureau voor de Statistiek, CBS). CBS Statline. Available at: http://statline. cbs.nl. Accessed May 1, 2013.

19. European Central Bank. ECB: Euro foreign exchange reference rates. Available at: https:/www.ecb.europa.eu/stats/ exchange/eurofxref/html/index.en.html. Accessed October 24, 2014.

20. Organisation for Economic Co-operation and Development (OECD). OECD Territorial Reviews: Randstad Holland, Netherlands. Paris: OECD; 2010.

21. Chandratheva A, Geraghty OC, Luengo-Fernandez R, Rothwell PM. $\mathrm{ABCD}^{2}$ score predicts severity rather than risk of early recurrent events after transient ischemic attack. Stroke 2010;41:851-856.

22. O’Donnell MJ, Xavier D, Liu L, et al. Risk factors for ischaemic and intracerebral haemorrhagic stroke in 22 countries (the INTERSTROKE study): a case-control study. Lancet 2010;376:112-123.

\section{Neurology ${ }^{\circledR}$ Genetics Call For Papers}

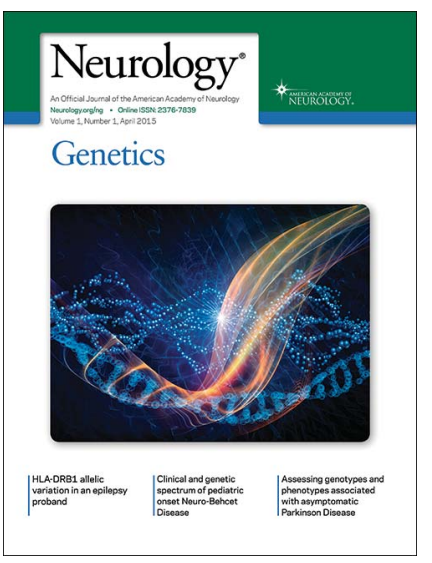

Neurology: Genetics is an open access, online only journal that will provide neurologists with outstanding original contributions that elucidate the role of genetic and epigenetic variation in diseases and biological traits of the central and peripheral nervous system. We welcome all submissions. For more information on how to submit, visit http://www.neurology.org/site/ gen/gen2.xhtml. 